EDITORIAL

\title{
EPISTEMologia dAS CiÊNCIAS dA RELIGIÃo
}

O termo epistemologia é polivalente e inclui um leque abrangente de questões que abarcam desde teoria do conhecimento e da investigação, passando pela filosofia da ciência, até problemas teóricos intrínsecos à determinada práxis científica ou teoria da ciência - tratando-se de um conjunto de problemas filosóficos e científicos que surgiram e se desenvolveram a partir dos séculos XVII e XVIII, mas que receberam um nível de sofisticação técnica e de profissionalização, sobretudo, nos séculos XIX e XX (DUTRA, 2010; 2017). É verdade que, na tradição ocidental, problemas filosóficos sobre o conhecimento em geral estão presentes desde a antiguidade grega, especialmente no que concerne à distinção clássica entre saber racional - ou crença verdadeira e justificada - face da mera opinião ou crença. Mas é só na modernidade europeia que se intensificam investigações acerca dos limites do entendimento humano e da validade das fontes de seu conhecimento, em que pese o contexto de crítica às ciências metafísicas. Em parte, a crise da metafísica coincidiu com o sucesso da moderna ciência da natureza, cujo prestígio desafiou e suscitou reformulações teóricas e de método para as ciências humanas, enquanto fundamentação para o estudo da sociedade e da história (DILTHEY, 2010).

No Brasil em particular, em virtude da forte influência do positivismo na academia, os estudos sobre epistemologia foram de fundamental importância para superar preconceitos e abrir espaço para a seriedade dos estudos no vasto campo das humanidades. Por esta razão se tornou comum, entre nós, desde os debates sobre reforma universitária em fins dos anos sessenta (1968), pesquisas dedicadas à epistemologia das ciências humanas: cujo intuito era o de acompanhar a démarche da atividade científica, determinando suas leis, o fio condutor de seus problemas e suas condições sociais e ideológicas (JAPIASSU, 1994); neste sentido, ela se desenvolveu preocupada em examinar o problema da fundamentação das ciências humanas, seus paradigmas e modelos (DominguEs, 2004). Contudo, talvez mais do que qualquer outro campo de pesquisa acadêmica no âmbito das ciências humanas e sociais, os estudos de religião jamais receberam a atenção que lhes é de direito. Pelo menos até a década de sessenta do século passado o interesse pela religião, enquanto 
objeto de pesquisa, contava apenas com estudos isolados, pois fora relegado basicamente às instituições eclesiásticas e só paulatinamente conquistou cidadania acadêmica a partir da década de setenta (OLIVEIRA, 2014).

Se uma das principais tarefas da epistemologia é refletir sobre os fundamentos da ciência, em nosso caso, ela significa ocupar-se das especificidades das ciências da religião. Claro que este debate vai além de discussões meramente teóricometodológicas, pois existem muitos condicionantes extrateóricos e até circunstanciais que atuam no processo de consolidação de uma comunidade científica. Porém, numa compreensão mais ampla do que seja epistemologia, devemos considerar estes condicionantes também como parte integrante da reflexão epistemológica, a propósito de sua dimensão político-acadêmica e do engajamento necessário de seus promotores para a efetivação de uma cultura epistemológica da área (PONDÉ, 2008). No entanto, seja para fins de política-acadêmica, seja para fins de justificação teórica, a questão nuclear para qual dirigimos nossa atenção se deixa formular da seguinte maneira: afinal, em que consiste o empreendimento científico que designamos aqui de estudos de religião?

No contexto europeu, esta disciplina se institucionalizou a partir da segunda metade do século XIX, como resultante de inúmeros processos históricos e científicos, tais como o colonialismo europeu, as missões evangelizadoras e o contato com religiões extracristãs; contribuíram também as descobertas arqueológicas, os progressos linguístico-comparados da filologia e o florescimento das ciências empíricas do homem, sobretudo nos campos da sociologia, da etnologia ou antropologia cultural, e da psicologia da religião (LANCZKOWSKI, 1980). Tradicionalmente, o debate sobre a epistemologia do estudo das religiões (epistemology of the study of religions) se concentrou na tarefa de promover o reconhecimento de um campo específico de pesquisa, enquanto uma disciplina autônoma e coerente, particularmente distinta da teologia (WAARDENBURG, 1999), e com teorias e métodos próprios de pesquisa (WHALING, 1995).

Por sua vez, como já se indicou, o processo de gênese dos estudos de religião no Brasil teve lugar na década de sessenta do século passado, iniciando com a constituição de espaços de interface entre teólogos e cientistas sociais, o que gradativamente conduziu, na década de setenta, para o surgimento dos primeiros Programas de Pós-graduação em Ciência(s) da Religião. Em virtude deste 
empreendimento colaborativo que marcou não só o pontapé inicial da área, mas também seu desenvolvimento entre nós desde então, quando dizemos de estudos de religião como campo de pesquisa, temos em mente normalmente a área de Ciências da Religião e Teologia - nomenclatura que se tornou recentemente nome oficial da área na CAPES (2016), muito embora ela já constasse em suas principais comunidades acadêmicas, tais como a Sociedade de Teologia e Ciências da Religião (SOTER) e a Associação Nacional de Pós-graduação e Pesquisa em Teologia e Ciências da Religião (ANPTECRE).

Podemos afirmar com razão que preocupações de ordem epistemológica estiveram presentes desde o início, quando a área sequer existia, em virtude da necessidade de legitimação dos estudos de religião diante de resistências tanto da ala conservadora das igrejas, quanto do positivismo da academia (FAUSTINO, 2012). Porém, este debate ganhou relevo especialmente a partir da década de noventa do século XX com a ampliação dos programas de pós-graduação, seguida da publicação de uma série de coletâneas centrais para a consolidação da área, cujas contribuições podem ser consideradas variações sobre problemas epistemológicos: por exemplo, o interesse teológico de abertura e diálogo com a cultura (ANJOS, 1996); o debate sobre a afirmação da(s) ciência(s) da religião (TEIXEIRA, 2008, $1^{\mathrm{a}}$ ed. 2001) e sobre seus desafios contemporâneos (GUERRIERO, 2003); o papel da fenomenologia nos estudos interdisciplinares da área (DREHER, 2003) e os constituintes de seu espectro disciplinar (USARSKI, 2007), que conduziram, adiante, às asserções sobre sua maioridade acadêmica (CRUZ; MORI, 2011); por fim, destacam-se ainda a publicação do compêndio da área que dedicou uma seção especial para a epistemologia da ciência da religião (PASSOS; USARSKI, 2013) e as discussões sobre o futuro da área no Brasil (ARAGÃo; CABRAL; VALLE, 2014).

Como consequência e amadurecimento destes debates acadêmicos, Epistemologia das Ciências da Religião corresponde atualmente a uma dentre as oito subáreas da árvore de conhecimento da área de Ciências da Religião e Teologia na CAPES. Em síntese, o objetivo deste ramo de pesquisa é refletir tanto sobre o estatuto científico das Ciências da Religião, quanto sobre seus problemas de método e objeto (SENRA, 2015). A seu lado e de maneira complementar, consta a subárea Teologia fundamental-sistemática. Nestes dois casos o que se tem em vista é fomentar discussões sobre os fundamentos do estudo da religião, quer de matiz 
teológica, quer de orientação científico-religiosa. O fato de que a própria área oficialize um ramo de estudos sobre epistemologia e teologia fundamental indica de maneira decisiva o reconhecimento da relevância do assunto.

Estudos de religião: epistemologias é o tema deste dossiê cuja iniciativa louvável visa dar prosseguimento a este debate só esboçado aqui em seus contornos gerais. Dado que nosso campo de pesquisa envolve várias epistemes, no sentido de subdisciplinas específicas ou auxiliares, cumpre indagar sobre os modos plurais pelos quais investigamos a religião; ou seja, como se distinguem e se complementam as pesquisas teológicas e científico-religiosas, de que maneira empregamos teorias e métodos em nossas análises e como validamos as nossas diversas perspectivas assumidas a cada vez. Ademais, esta discussão conecta-se, naturalmente, com problemas de natureza metateórica, enquanto reflexões sobre o processo de teorização e o modo como trabalhamos a relação entre teoria e dados. Neste sentido, a revista Interações propõe-se não só um assunto crucial para a área como um todo, mas também está em sintonia com as pesquisas mais avançadas hoje no Brasil e no exterior.

Em última análise, este dossiê espera proporcionar ao leitor uma atualização do debate epistemológico contemporâneo, levando em conta as diversas possibilidades teóricas e metodológicas da área, o que por si só presta um serviço inestimável aos estudos de religião brasileiros. Em certo sentido, pode-se argumentar que polêmicas epistemológicas são infindáveis, o que frequentemente desperta entre seus críticos a suspeita de se recair em esforços vãos. Mas se questões epistemológicas jamais cessam por força de seu caráter provisório e inconclusivo; no entanto, não parece certo considerá-las ineficazes ou desprovidas de valor. Pelo contrário! Não seria o caso de concebê-las como responsáveis pela vitalidade de uma comunidade acadêmica? A nosso ver, pelo menos, deveríamos celebrá-las como uma virtude epistêmica: pois elas reforçam o compromisso de nunca se perder de vista os problemas fundamentais da área.

Meus cumprimentos ao Prof. Flávio A. Senra Ribeiro pelo gentil convite para a redação deste editorial, um colega com quem desfruto o privilégio da convivência e do aprendizado no Programa de Pós-graduação em Ciências da Religião (PPGCR) da Pontifícia Universidade Católica de Minas Gerais (PUC Minas); beneficio-me ainda da honra de tê-lo como supervisor do meu estágio pós-doutoral iniciado no ano de 
2017 e ainda em curso, financiado pelo Programa Nacional de Pós-doutorado (PNPD) da CAPES. Desejo a todos(as) uma proveitosa leitura.

Davison Schaeffer de Oliveira Doutor e pós-doutor em Ciência da Religião pela Universidade Federal de Juiz de Fora, professor colaborador do Programa de Pós-graduação em Ciências da Religião da Pontifícia Universidade Católica de Minas Gerais e pesquisador de pós-doutorado PNPD/CAPES (PUC Minas).

\section{REFERÊNCIAS}

ANJOS, Márcio Fabri dos (Org.). Teologia profissão. São Paulo: Editoras Loyola, 1996.

ARAGÃO, Gilbraz; CABRAL, Newton; VALLE, Edênio (Orgs.). Para onde vão os estudos da religião no Brasil. São Paulo: ANPTECRE, 2014.

CRUZ, Eduardo R. da; MORI, Geraldo de (Orgs.). Teologia e Ciências da Religião: a caminho da maioridade acadêmica no Brasil. São Paulo: Paulinas, 2011.

DILTHEY, Wilhelm. Introdução às Ciências Humanas: tentativa de uma fundamentação para o estudo da sociedade e da história. Trad. Marco Antônio Casanova. Rio de Janeiro: Forense Universitária, 2010.

DOMINGUES, Ivan. Epistemologia das ciências humanas: positivismo e hermenêutica-tomo 1. São Paulo: Edições Loyola, 2004.

DREHER, Luís Henrique. A essência manifesta: a fenomenologia nos estudos interdisciplinares da religião. Juiz de Fora: Editora UFJF, 2003.

DUTRA, Luiz Henrique de Araújo. Introdução à Epistemologia. São Paulo: Editora UNESP, 2010.

DUTRA, Luiz Henrique de Araújo. Introdução à teoria da ciência. 4 ed. Florianópolis: Editora da UFSC, 2017.

GERRIERO, Silas (Org.). O Estudo das Religiões: desafios contemporâneos. São Paulo: Paulinas, 2003.

JAPIASSU, Hilton. Introdução às Ciências Humanas: análise de epistemologia histórica. São Paulo: Editora Letras \& Letras, 1994.

\section{LANCZKOWSKI, Günter. Einführung in die Religionswissenschaft.}

Darmstadt: WBG, 1980.

OLIVEIRA, Pedro Assis Ribeiro de. Ciências da Religião e Teologia: evolução e situação desde a perspectiva brasileira. In: ARAGÃO, Gilbraz; CABRAL, Newton; 
VALLE, Edênio (Orgs.). Para onde vão os estudos da religião no Brasil. São Paulo: ANPTECRE, 2014, p. 47-64.

PASSOS, João Décio; USARSKI, Frank (Org.). Compêndio de Ciência da Religião. São Paulo: Paulinas; Paulus, 2013.

PONDÉ, Luiz Felipe. Em busca de uma cultura epistemológica. In: TEIXEIRA, Faustino (Org.). A(s) Ciências(s) da Religião no Brasil: afirmação de uma área acadêmica. 2 ed. São Paulo: Paulinas, 2008, p. 11-66.

SENRA, Flávio. Estudos de Ciência (s) da (s) Religião (ões) e Teologia no Brasil: Situação atual e perspectivas. Revista de Estudos da Religião (REVER), v. 15, n. 2, p. 196-214, 2015.

TEIXEIRA, Faustino (Org.). A(s) Ciências(s) da Religião no Brasil: afirmação de uma área acadêmica. 2 ed. São Paulo: Paulinas, 2008.

TEIXEIRA, Faustino. O processo de gênese da (s) ciência (s) da religião na UFJF. Numen: revista de estudos e pesquisa da religião, Juiz de Fora, v. 15, n. 2, p. 537550, 2012.

WAARDENBURG, Jacques. Classical Approaches to the Study of Religion. Berlin: de Gruyter, 1999.

WHALING, Frank (Ed.). Theory and Method in Religious Studies:

Contemporary Approaches to the Study of Religion. Berlin; New York: de Gruyter, 1995 . 